\title{
IRONIC EFFECTS OF MORAL MOTIVATION: WHY WORKING TOWARD A MORAL GOAL REDUCES SUBSEQUENT PERSPECTIVE TAKING
}

Tomas Ståhl

University of Illinois at Chicago

Naomi Ellemers

Utrecht University, the Netherlands

\begin{abstract}
People generally consider it more important to reach moral standards than other types of standards (e.g., competence). In this article it is argued that pursuit of goals that have implications for one's morality (vs. competence) therefore leads to increased engagement of the central executive. A first study demonstrates that individuals perform better on an executive control task when informed that it has implications for their morality (vs. competence). Consistent with previous research on executive control exertion, a second study demonstrates that executive control is impaired after working on a task that supposedly has implications for one's morality (vs. competence), which in turn reduces perspective taking. It is concluded that pursuit of a moral goal can ironically lead to subsequent moral failures as a result of impaired executive control.
\end{abstract}

Keywords: morality, executive control, perspective taking

Failures to reach moral standards are perceived as more diagnostic of individual dispositions than are failures to reach other standards (e.g., competence; Skowronski \& Carlston, 1987). Furthermore, moral traits generally have a greater impact on overall impression formation and subsequent behavior than non-moral traits (Pagliaro, Brambilla, Sacchi, D’Angelo, \& Ellemers, 2013; for an overview, see Bram-

The research reported in this article was funded by a Spinoza grant awarded to the second author. The article was prepared while the first author was working at Leiden University, the Netherlands. We are very grateful to Elise Roovers and Floor Stuit for assistance in data collection.

Correspondence concerning this article should be addressed to Tomas Ståhl, Department of Psychology, University of Illinois at Chicago, m/c 285, 1007 W. Harrison St., Chicago, IL 60607-7137; E-mail: tstahl@uic.edu. 
billa \& Leach, 2014). It is therefore not surprising that individuals attach particular importance to the pursuit of morally prescribed goals, as compared to goals that are justified based on other types of norms (Ellemers, Pagliaro, Barreto, \& Leach, 2008; Leach, Ellemers, \& Barreto, 2007). For instance, participants who performed an Implicit Association Task (IAT) displayed less implicit bias, and showed evidence of increased stimulus attention and response monitoring on EEG measures when the moral implications of this task had been emphasized (Van Nunspeet, Ellemers, Derks, \& Nieuwenhuis, 2014).

In this article we propose that one of the consequences of framing a goal in moral terms is that it increases engagement of the central executive. Such a response during pursuit of particularly important goals would be adaptive, because a high executive control capacity enables persistence even in the face of obstacles to goal attainment. Furthermore, there is some evidence from the self-regulation literature that engagement of the central executive increases in situations in which reaching a certain standard is perceived as a motivational necessity (Ståhl, Van Laar, \& Ellemers, 2012; cf. Koch, Holland, \& van Knippenberg, 2008; Koch, Holland, Hengstler, \& van Knippenberg, 2009).

We are by no means the first to suggest that the central executive is involved in moral behavior. Executive control is involved in the inhibition of various behaviors that are generally considered as immoral, such as selfish acts (Achtziger, AlósFerrer, \& Wagner, 2015), cheating for financial gain (Gino, Schweitzer, Mead, \& Ariely, 2011; Mead, Baumeister, Gino, Schweitzer, \& Ariely, 2009), and aggressive responses to provocation (DeWall, Baumeister, Stillman, \& Galliot, 2007; Stucke \& Baumeister, 2006; Vohs, Glass, Maddox, \& Markman, 2011). Furthermore, many behaviors that are considered as moral also require perspective taking. Notably, numerous studies, from all major areas of psychology have demonstrated that executive control is required in order to actively take the perspective of another person (e.g., Apperly, Samson, \& Humphreys, 2009; Brown-Schmidt, 2009; Carlson, Mandell, \& Williams, 2004; Carlson, Moses, \& Breton, 2002; Carlson, Moses, \& Claxton, 2004; Epley, Keysar, Van Boven, \& Gilovich, 2004; Fennis, 2011; Hughes \& Ensor, 2007; Nilsen \& Graham, 2009; Pellicano, 2007; Wardlow, 2013). These studies all have in common that they connect engagement of the central executive to demanding psychological processes (i.e., inhibition, perspective taking), that in turn are required for many behaviors that are generally considered as morally commendable. By contrast, we propose in the present article that, because reaching moral standards is such a high priority, the central executive should be recruited whenever one's moral reputation is contingent on one's performance on a task. Thus, independent of the cognitive demands of the task itself, the mere realization that performing well (vs. poorly) on the task has moral implications should increase involvement of the central executive.

The present research examines two predictions derived from this line of reasoning. In Study 1 we investigate whether executive control is facilitated during the pursuit of a moral goal as compared to a non-moral goal, while keeping the actual task demands constant across conditions. In Study 2 we examine the downstream consequences of this phenomenon. In particular, we examine whether the 
increased involvement of the central executive during moral goal pursuit may have ironic consequences for subsequent behavior. Numerous studies have demonstrated that reliance on the central executive leads to impaired executive control on subsequent tasks (e.g., Hagger, Wood, Stiff, \& Chatzisarantis, 2010; Inzlicht \& Schmeichel, 2012; Muraven \& Baumeister, 2000). Based on this earlier work, we therefore investigate whether the pursuit of an initial moral (vs. non-moral) goal leads to subsequent impairments in executive control. Furthermore, we also investigate the downstream consequences of this process for perspective taking. Specifically, because actively taking the perspective of someone else relies on the central executive, we expected pursuit of an initial moral (vs. non-moral) goal to impair subsequent perspective taking. Finally, we expected this effect to be mediated by impairments in executive control.

\section{STUDY 1}

The first study examined whether framing a task as having implications for one's morality (vs. competence) led to increased engagement of the central executive. In order to investigate this possibility, a task that assesses domain general executive control (a Stroop task) was framed either in terms of its moral or non-moral implications. To the extent that framing a task as relevant for one's morality increases engagement of the central executive, performance on the executive control task should be improved in this condition as compared to when the task was framed as having implications for one's competence.

We examine two different indicators of executive function based on performance on the Stroop task (Stroop, 1935). First, we examine differences in average response time (RT) on incongruent (vs. neutral) Stroop trials. Average RTs on the Stroop task have frequently been used as an indicator of general executive control efficiency (e.g., Inzlicht, McKay, \& Aronson, 2006; Johns, Inzlicht, \& Schmader, 2008; Richeson et al., 2003; Richeson \& Shelton, 2003). Second, we also examine intra-individual variability in response time on incongruent (vs. neutral) Stroop trials. Intra-individual RT variability on executive control tasks has frequently been used in clinical psychology as an indicator of consistency in executive control (e.g., Fjell, Westlye, Amlien, \& Walhovd, 2011; Jensen, 1992; Johnson, Kelly, Bellgrove, et al., 2007; Simmonds, Fotedar, Suskauer, Pekar, Denckla, \& Mostofsky, 2007). Inconsistency in executive control (i.e., high RT variability) has been linked to a broad range of clinical conditions, including frontal lobe injury (Stuss, Murphy, Binns, \& Alexander, 2003), posttraumatic stress (Swick, Honzel, Larsen, \& Ashley, 2013), ADHD (Tamm, Narad, Antonini, O’Brien, Hawk, \& Epstein, 2012), and sleep deprivation (Chuah, Venkatraman, Dinges, \& Chee, 2006).

Importantly, observations of meaningful differences in the consistency of executive control are not confined to clinical populations, but have been found in healthy subjects as well (e.g., Bellgrove, Hester, \& Garavan, 2004; Manly, Davison, Heutink, Galloway, \& Robertson, 2000; Shammi, Bosman, \& Stuss, 1998; West, Murphy, Armilio, Craik, \& Stuss, 2002). Of particular relevance for the present 
purposes, there is evidence that RT variability on executive control tasks is particularly sensitive to cognitive fatigue. For example, RT variability on the Stroop task has been shown to increase over time, even when no change in average RT over time was observed (Rauch \& Schmitt, 2009). Similar effects of cognitive fatigue on RT variability have been found on other executive control tasks as well (Boksem, Meijman, \& Lorist, 2006). Thus, there is strong evidence that average RT and RT variability on executive control tasks are valid indicators of general executive control performance, and consistency in executive control performance, respectively. In the present study we therefore assess whether-compared to competence instructions-moral task instructions induce increased engagement of the central executive, by examining whether we observe reduced average RTs, as well as reduced RT variability on the Stroop task.

\section{METHOD}

Participants and Design. Seventy-eight students (62 women, 16 men, $M_{\text {age }}=20$, $S D_{\text {age }}=2.14$ ) at Leiden University were randomly assigned to either the morality condition or to the competence condition. The study lasted approximately 20 minutes and participants received $€ 2$ for their time in the laboratory.

Procedure. Upon arrival in the lab, each participant was seated in a separate cubicle equipped with a computer used to present all the information about the study as well as to collect the data. Participants in the morality condition were informed that the purpose of this study was to examine the tendency to engage in moral versus immoral behavior. In particular, it was stated, they were to perform a task on which performance has been found to be a good predictor of moral behavior in different situations. By contrast, participants in the competence condition were informed that the purpose of the study was to examine the ability to quickly and accurately process complex information. In particular, it was stated, they were to perform a task on which performance has been found to be a good predictor of their ability to process complex information in different situations. These same instructions were used in prior research to present an Implicit Association Task (IAT) as either indicating participants' morality or their competence (Van Nunspeet, Derks, Ellemers, \& Nieuwenhuis, 2015; Van Nunspeet et al., 2014). This prior research confirmed that participants reported equal levels of task engagement, and considered the task as an equally valid diagnostic tool across conditions. However they indicated being more concerned about the (social) implications of their task performance after moral compared to competence instructions. After receiving these task instructions, all participants carried out the same Stroop task to assess their current executive control capacity. The Stroop task consisted of 60 trials, of which 20 trials were congruent (red in red ink or blue in blue ink), 20 trials were neutral (XXXX in red or blue ink), and 20 trials were incongruent (red in blue ink or blue in red ink). The order of the trials was randomized. Participants were instructed to ignore the semantic meaning of each stimulus and indicate the color in which it was presented. It was further stated that accuracy and speed were of equal importance.

Upon completion of the Stroop task we checked comprehension of the manipulation with two items. Specifically, we asked participants to what extent they 
agreed that the task measured their morality versus their ability to process complex information $(1=$ not at all, $7=$ very $m u c h)$. Finally, participants were fully debriefed, thanked, and paid for their participation.

\section{RESULTS AND DISCUSSION}

Manipulation Checks. Participants in the morality condition agreed more with the statement that the Stroop task assessed their morality $(M=4.38, S D=2.16)$ than participants in the competence condition $(M=2.13, S D=1.59), F(1,76)=27.58, p$ $<.001, \eta_{p}^{2}=.27$. Participants in the competence condition agreed more with the statement that the Stroop task measured their ability to process complex information $(M=5.00, S D=1.73)$ than participants in the morality condition $(M=3.95, S D$ $=1.95), F(1,76)=6.35, p=.01, \eta_{p}^{2}=.08$. Thus, the manipulation was perceived as intended.

Executive Control. Differences in executive control were examined in two different ways. First we assessed general executive control performance based on average response time (RT) on incongruent (vs. neutral) trials (the classic Stroop effect). A larger Stroop effect indicates lower overall executive control. Second, consistency of cognitive control was assessed by comparing differences in intraindividual RT variability on incongruent (vs. neutral) Stroop trials. The more RT variability observed (i.e., the higher the $S D$ ) on incongruent (vs. neutral) trials, the more the individual's executive control capacity was fluctuating throughout the Stroop task, indicating inconsistent executive control performance (e.g., Boksem et al., 2006; Rauch \& Schmitt, 2009). To correct for the typical positive skew associated with response times, all analyses were performed on log-transformed response times. However, we report results in milliseconds for ease of interpretation. One outlier more than $3 S D$ away from the mean was removed.

A mixed 2 (task frame: morality/competence) $\times 2$ (trial type: incongruent/neutral) ANOVA on average RT yielded a main effect of trial type, $F(1,75)=21.10, p$ $<.001, \eta_{p}^{2}=.22$. Consistent with the classic Stroop effect, responses were slower on incongruent trials $(M=462, S D=90)$ than on neutral trials $(M=438, S D=64)$. However, this effect was qualified by a marginally significant interaction, $F(1,75)$ $=2.82, p<.10, \eta_{p}^{2}=.04$. Consistent with our hypothesis, the Stroop effect was more than double in size in the competence condition, $F(1,37)=16.26, p=.001, \eta_{p}^{2}=.31$; as compared to the morality condition, $F(1,38)=5.31, p=.03, \eta_{p}^{2}=.12$. This pattern of results (see Figure 1) suggests that executive control was (marginally) enhanced while working on a task with implications for one's morality (vs. competence).

To assess the effects of a moral (vs. competence) goal on consistency in executive control performance, we then examined differences in intra-individual RT variability on incongruent versus neutral Stroop trials. A mixed 2 (task frame) by 2 (trial type) ANOVA yielded a significant effect of trial type, $F(1,75)=30.71, p<$ $.001, \eta_{p}^{2}=.29$; qualified by the predicted interaction, $F(1,75)=5.00, p=.03, \eta_{p}^{2}=$ .06. This interaction is depicted in Figure 2. Follow up analyses revealed the pattern we anticipated: there was considerably more variability in response times on incongruent trials than on neutral trials in the competence condition, $F(1,37)=$ $31.46, p<.001, \eta_{p}^{2}=.46$. This effect was considerably smaller in the morality condi- 


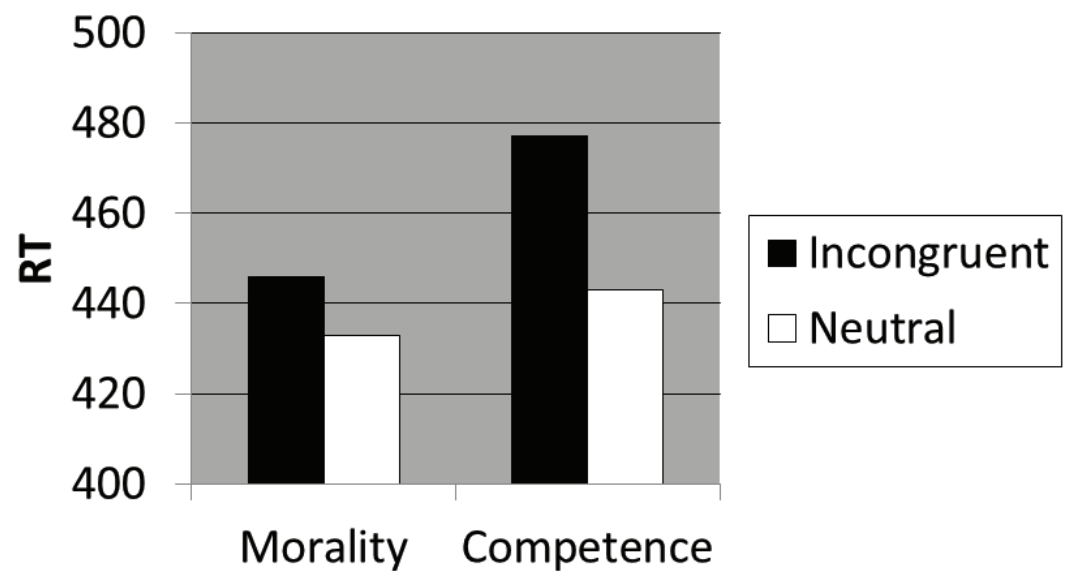

FIGURE 1. Average response time on the Stroop task as a function of trial type and whether the Stroop task was framed as relevant for morality or competence (Study 1).

tion, $F(1,38)=5.28, p=.03, \eta_{p}^{2}=.12$, indicating that executive control remained more stable throughout the Stroop task in the morality condition than in the competence condition.

To summarize, consistency in executive control was enhanced when the task was framed as relevant for one's morality (vs. competence). That is, under moral task instructions, increased control during the Stroop task was evident from the reduced variability in intra-individual response times. A similar pattern emerged, but was only marginally significant, when considering mean differences in response time. These findings provide support for our prediction that a moral goal leads to increased engagement of the central executive. In the second study we turn to the consequences of having worked on a task on which performance has moral implications for subsequent executive control and ability to take the perspective of others-which is relevant to moral behavior in social interactions.

\section{STUDY 2}

There is broad agreement in the literature that engaging in a task that requires executive control (Time 1) leads to poorer performance on a subsequent executive control task (Time 2). The explanation of this phenomenon, however, is debated. According to limited resource models (e.g., Muraven \& Baumeister, 2000), this phenomenon occurs because executive control exertion relies on a limited cognitive resource that quickly gets depleted. By contrast, other researchers have proposed that the drop in executive control observed at Time 2 is due to a shift in motivation away from pursuit of demanding and aversive "have-to" goals, toward pursuit of more gratifying "want-to" goals (Inzlicht \& Schmeichel, 2012; Inzlicht, Schmeichel, \& Macrae, 2014). Regardless of whether the so-called "depletion effect" is motivational in nature, or due to limitations in executive control capacity, researchers are in agreement about the basic effect: Engaging the central executive 


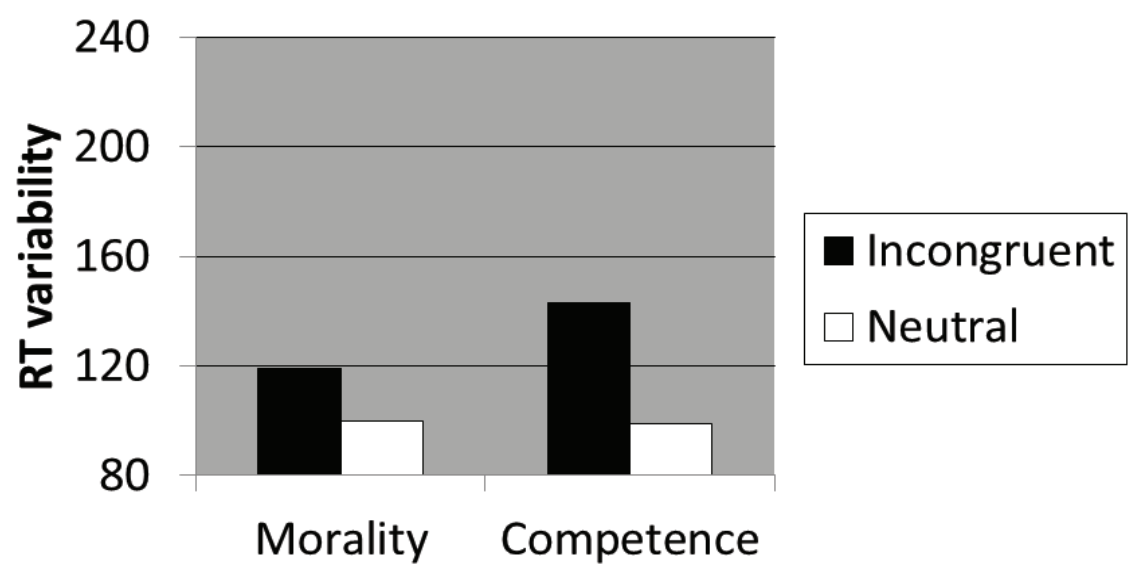

FIGURE 2. Variation (SD) in response time on the Stroop task as a function of trial type and whether the Stroop task was framed as relevant for morality or competence (Study 1).

in one task leads to impaired executive control on a subsequent task. We therefore hypothesized that working on a morally framed task should engage the central executive, and thereby lead to subsequent impairments in executive control. To test this hypothesis, the perceived implications (moral vs. competence) of an initial memory task were manipulated. Upon completion of this initial task, subsequent executive control performance was measured with a Stroop task. To the extent that working on the morally relevant memory task increased engagement of the central executive, subsequent Stroop performance should be impaired in this condition as compared to when the initial task was framed as having implications for one's competence.

Another purpose of the second study was to demonstrate that this effect undermines people's inclination to engage in subsequent perspective taking. We opted to focus on perspective taking for two reasons. First, as mentioned earlier in this article, there is converging evidence across various fields in psychology and neuroscience that avoiding egocentrism, and actively taking the perspective of others relies on executive control (e.g., Apperly et al., 2009; Brown-Schmidt, 2009; Carlson et al., 2002; Epley et al., 2004; Hughes \& Ensor, 2007). Perspective taking should therefore be sensitive to variations in motivation and capacity to exert executive control. Second, perspective taking is closely associated with empathic concern in response to the suffering of others (Davis, 1983; Lamm, Batson, \& Decety, 2007). Indeed, perspective taking as well as empathic concern predicts various prosocial behaviors (Batson et al., 2003; Eisenberg \& Miller, 1987; Underwood \& Moore, 1982). For instance, perspective taking has been found to counteract explicit as well as implicit racial bias (e.g., Batson et al., 1997; Dovidio et al., 2004; Todd, Bodenhausen, Richeson, \& Galinsky, 2011). Thus, to the extent that engaging in an initial morally framed task impairs subsequent perspective taking, it should have implications for a broad range of behaviors in the moral domain. Our prediction was that working on an initial moral (vs. competence) task (Time 1) should impair 
executive control on a second task (Time 2), which in turn should have negative consequences for subsequent perspective taking. Thus, we expected the drop in executive control caused by working on an initial moral task to mediate the negative effect on subsequent perspective taking.

\section{METHOD}

Participants and Design. Forty-seven students at Leiden University (33 women, 14 men, $M_{\text {age }}=23, S D_{\text {age }}=3.86$ ) were randomly assigned either to the morality condition or to the competence condition. The study lasted approximately 20 minutes and participants received $€ 2$ for their time in the laboratory.

Procedure. The cover story was the same as in Study 1 . This time, however, we framed a recall test (Kinderman, Dunbar, \& Bentall, 1998) as having implications for one's morality (vs. competence). Because this test is relatively simple, we did not anticipate any effects of the framing manipulation on actual test performance. However, because framing the recall test as relevant for morality should increase demanding processes that rely on executive control, such as conflict monitoring (Van Nunspeet et al., 2014; cf. Inzlicht \& Gutsell, 2007) we still expected the moral (vs. competence) recall test to have negative consequences for executive control as measured after the recall test. Indeed, prior research (Van Nunspeet et al., 2014) has revealed that providing participants with moral task instructions may enhance cognitive responses (as indicated in EEG measures), even if this is not visible in overt behavior.

Upon completion of the memory test, participants were asked to participate in two further tests that were introduced as unrelated pilot tests for different studies. The purpose of the first test in this series allegedly was to try out a newly programmed computerized version of a psychological test. In reality, this pilot test was an identical Stroop task as the one used in Study 1. After completing the Stroop task participants were asked to participate in the pilot testing of some reading materials that had recently been translated into Dutch. In reality this third assignment was a message interpretation task developed to measure perspective taking (Sassenrath, Sassenberg, \& Scholl, 2014; cf. Epley et al., 2004; Keysar, 1994). For this task, participants read four different stories describing an interaction between a protagonist and one or several other individuals. The stories provided the reader with privileged information about the true communication intentions of the protagonist, making it clear that he was not being serious. This information, however, was clearly not available to the protagonist's interaction partners. Participants were then asked to indicate whether the interaction partners would realize that the protagonist was not being serious $(1=$ not at all, $7=$ completely $)$. Understanding that the interaction partners would not realize the protagonist's true intentions requires perspective taking. Thus, lower scores on these items indicate higher levels of perspective taking. Responses were recoded and averaged to create a reliable perspective-taking scale on which higher scores indicated more perspective taking $(\alpha=.62)$. After the perspective-taking task, comprehension of the morality (vs. competence) manipulation was checked with the same two items 
as in Study 1. Finally, participants were fully debriefed, thanked, and paid for their participation.

\section{RESULTS AND DISCUSSION}

Manipulation Checks. Participants in the morality condition agreed more with the statement that the memory test assessed their morality $(M=4.22, S D=2.24)$ than participants in the competence condition $(M=2.33, S D=1.66), F(1,45)=10.83, p$ $=.002, \eta_{p}^{2}=.19$. Participants in the competence condition agreed more with the statement that the memory test measured their ability to process complex information $(M=5.54, S D=1.69)$ than participants in the morality condition $(M=4.48$, $S D=1.90), F(1,45)=4.10, p<.05, \eta_{p}^{2}=.08$. Thus, the manipulation was perceived as intended.

Memory Test Performance. The maximum score on the memory task was 29. As anticipated, scores on this task were generally very high $(M=26.51, S D=1.91)$, and framing the task as relevant for morality $(M=26.82, S D=1.50)$ did not significantly improve recall compared to when the task was framed as relevant for competence $(M=26.21, S D=2.23), F(1,45)=1.24, p=.27, \eta_{p}^{2}=.03$.

Executive Control. This time we used the Stroop task to examine variability in response time as an indicator of executive control after performing the (memory) task with moral (vs. non-moral) implications. The data of two participants were lost due to technical problems. All analyses were once again performed on logtransformed response times to correct for positive skew. However, we report response times in milliseconds for ease of interpretation.

As in Study 1, we first examined differences in average response times. A mixed 2 (task frame) by 2 (trial type) ANOVA yielded slower responses on incongruent trials $(M=467, S D=153)$ than on neutral trials $(M=426, S D=100)$, replicating the classic Stroop effect, $F(1,43)=18.50, p<.001, \eta^{2}=.30$. Contrary to Study 1 , the predicted interaction effect did not reach marginal significance, $F(1,43)=1.96, p$ $=.17, \eta_{p}^{2}=.04$. However, as expected, the Stroop effect was considerably larger in the morality condition, $F(1,22)=22.84, p<.001, \eta^{2}=.51$; than in the competence condition, $F(1,21)=3.20, p=.09, \eta_{p}^{2}=.13$. Thus, having worked on an initial task with implications for one's morality (vs. competence) tended to impair the average ability to suppress pre-potent responses (see Figure 3).

We then examined differences in executive control consistency by subjecting intra-individual RT variability scores to a mixed 2 (task frame) by 2 (trial type) ANOVA. This analysis yielded a significant effect of trial type, $F(1,43)=18.96$, $p=.001, \eta_{p}^{2}=.31$; qualified by the predicted interaction effect, $F(1,43)=8.64, p=$ $.005, \eta_{p}^{2}=.17$. This interaction is depicted in Figure 4. After having performed the memory test under moral instructions, we observed more variability in response times on incongruent trials than on neutral trials on the subsequent Stroop task, $F(1,22)=32.45, p<.001, \eta_{p}^{2}=.60$. No such effect emerged after performing the memory task under competence instructions, $F(1,21)=.84, p=.37, \eta_{p}^{2}=.04$. Thus, the ability to exert executive control consistently throughout the Stroop task was considerably impaired after working on an initial task with implications for one's morality. Similar increases in RT variability have been observed under other con- 


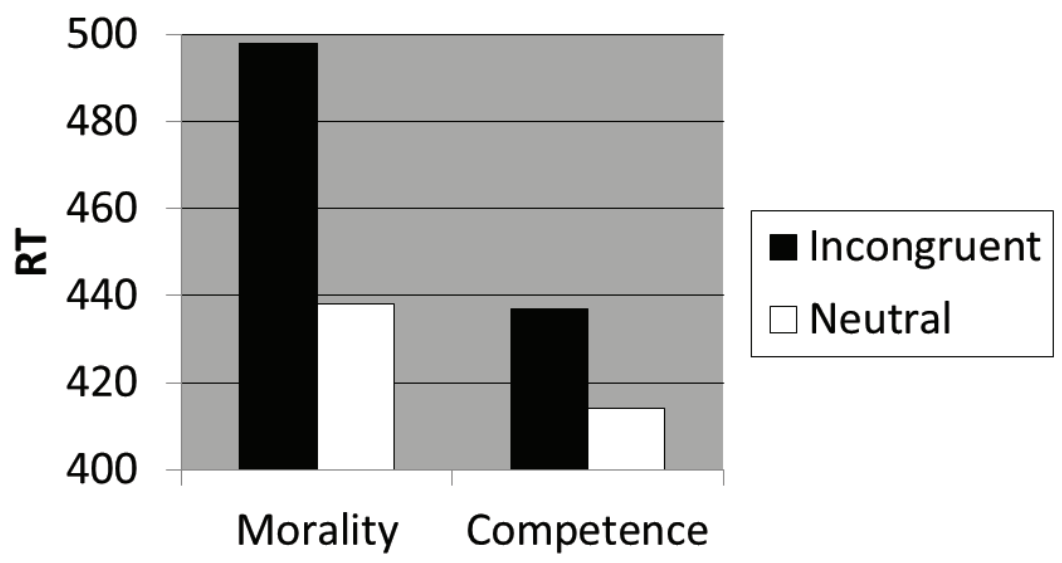

FIGURE 3. Average response time on the Stroop task as a function of trial type and whether the preceding recall task was framed as relevant for morality or competence (Study 2).

ditions that reduce executive control (e.g., Boksem et al., 2006; Rauch \& Schmitt, 2009). Importantly, no such signs of impaired cognitive control were evident after working on an initial task with implications for one's competence.

As anticipated, after having performed another task allegedly assessing one's morality or competence, the direction of the effect observed on the Stroop task was reversed compared to Study 1 . That is, after having performed a task framed as relevant for morality (vs. competence), participants showed signs of impaired (rather than improved) executive control. As in Study 1, the predicted effect was significant for the observed variability in response times, and we found a similar but nonsignificant pattern when comparing the mean response times across conditions. This finding is consistent with research suggesting that RT variability during an executive control task may be a more sensitive measure of cognitive exhaustion than average RT (Rauch \& Schmitt, 2009).

Perspective Taking and Mediation Analyses. In line with the prediction, there was less evidence of successful perspective taking after having performed the first task under morality instructions $(M=5.52, S D=1.08)$ compared to when participants had performed the memory task under competence instructions $(M=6.13, S D=$ $0.89), F(1,45)=4.35, p<.05, \eta_{p}^{2}=.09$.

We then performed a series of regression analyses to examine whether executive control impairments (RT variability during the second task) mediated the effect of task framing (on the initial memory task) on perspective taking (the third task). The task framing manipulation was effect-coded (morality $=1$, competence $=-1$ ), and an executive control fluctuations score was computed for each participant (SD on Incongruent trials-SD on Neutral trials). Consistent with ANOVA results reported above, working on the morally framed memory task increased subsequent executive control fluctuations, $b=.09, p=.005$, and also reduced perspective taking, $b=-.30, p=.04$. When both task framing and executive control fluctuations were entered into the equation, executive control fluctuations predicted perspective taking, $b=-1.62, p=.009$, whereas the direct effect of task framing was no 


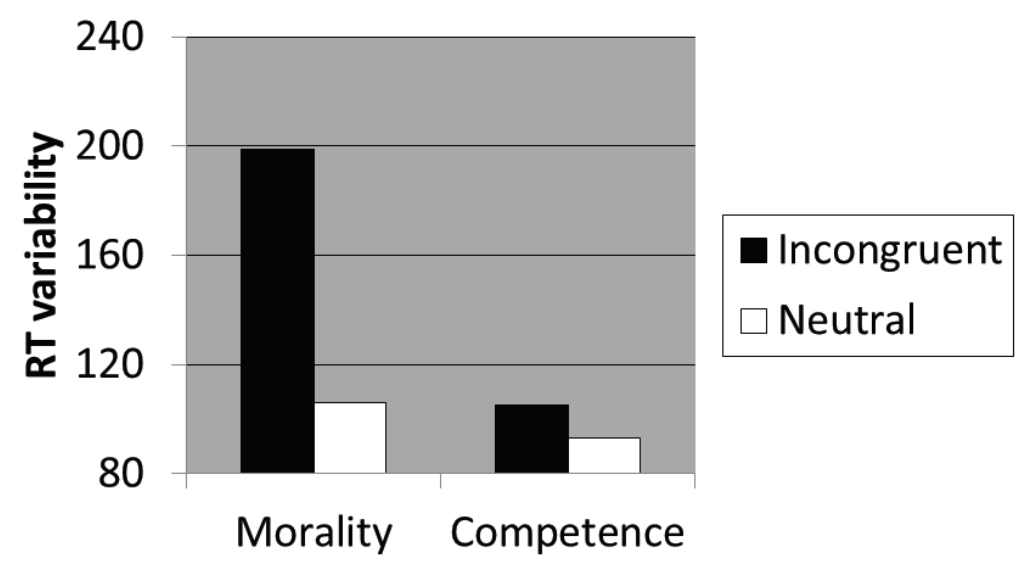

FIGURE 4. Variation (SD) in response time on the Stroop task as a function of trial type and whether the preceding recall task was framed as relevant for morality or competence (Study 2).

longer significant, $b=-.21, p=.13$. Bootstrapping analyses (Hayes, 2013, Model 4, 5000 resamples) confirmed that the indirect effect of task framing through executive control fluctuations was significant (indirect effect $=-.15, S E=.09,95 \%$ CI: -.39 to -.03). To conclude, working on a test framed as relevant for one's morality (vs. competence) impaired subsequent executive control. This, in turn, accounted for the negative effect of the morally relevant test on subsequent perspective taking. These findings are consistent with the results of Study 1, and further corroborate our line of reasoning.

\section{GENERAL DISCUSSION}

The present research examined a process through which trying to behave morally may lead to subsequent impairments in perspective taking. Based on recent observations that the pursuit of moral goals is perceived as particularly important (for overviews see: Ellemers, Pagliaro, \& Barreto, 2013; Ellemers \& Van den Bos, 2012), it was proposed that the pursuit of a moral (vs. non-moral) goal should increase engagement of the central executive. Such a response would be highly adaptive in that it enables persistence in goal pursuit even in the face of obstacles to goal attainment. However, according to limited resource models (e.g., Muraven \& Baumeister, 2000), as well as the process model of self-control depletion (Inzlicht \& Schmeichel, 2012; Inzlicht et al., 2014), it should also lead to impaired executive control over time. Ironically, to the extent that moral behaviors rely on cognitively demanding processes such as perspective taking, this may ultimately contribute to subsequent moral failures.

Two experiments provided support for our line of reasoning. The first study demonstrated that framing performance on a Stroop task as relevant for one's morality (vs. competence) facilitated executive control. The second study examined the consequences of this response over time and confirmed that executive control 
was impaired after working on a task on which performance was relevant for one's morality (vs. competence). Moreover, these impairments in executive control reduced the inclination to engage in subsequent perspective taking.

The primary contribution of the present work is that it demonstrates that being moral (vs. competent) not only is self-reported as being of particular importance due to its greater perceived social implications (Ellemers et al., 2013; Leach et al., 2007; Van Nunspeet et al., 2014, 2015), but that the pursuit of goals with moral implications in fact increases engagement of the central executive. We view these results as initial evidence of a highly adaptive response to situations in which goal attainment has particularly important social implications for the actor (Brambilla \& Leach, 2014; Ellemers et al., 2013). This response ensures sufficient allocation of attention to the task at hand, as well as persistence in goal pursuit when faced with obstacles to goal attainment.

Another important implication of the present research is that it suggests a process through which the pursuit of a moral goal can lead to subsequent moral failures. Notably, we are not the first to propose such ironic effects of moral behavior. Monin and his colleagues have argued that having performed a moral act can serve as "moral credit" —or as a license — to subsequently engage in morally questionable behavior (Monin \& Miller, 2001; for an overview, see Merritt, Effron, \& Monin, 2010). For example, performing an act that signals a favorable attitude toward African Americans has been found to increase subsequent racial bias (Effron, Cameron, \& Monin, 2009). According to Effron and his colleagues, the initial act serves as a license to subsequently engage in morally questionable behavior. Furthermore, this effect only emerged among those who scored relatively high on modern racism, presumably because they are the ones who are inclined to favor Whites when they feel licensed to do so (Effron et al., 2009). The present research suggests that an additional contributor to such effects may be that performing the initial morally relevant act engages the central executive, and thereby undermines subsequent motivation and/or ability to take the perspective of others. Notably, we know from previous research that interracial interactions increase engagement of the central executive (Richeson et al., 2003; Richeson \& Shelton, 2003). Furthermore, this is primarily the case among individuals who score high on implicit racial bias (Richeson et al., 2003; Richeson \& Shelton, 2003). In light of such findings, combined with the present direct evidence that tasks with moral implications increase engagement of the central executive, we believe that impaired executive control might be another process through which performing an initial moral act can lead to subsequent moral failures.

Future research is needed to examine the extent to which impaired executive control contributes to ironic consequences of engaging in moral behavior. Studies incorporating moderating variables that can dissociate the role of motivation (Inzlicht \& Schmeichel, 2012), cognitive depletion (Muraven \& Baumeister, 2000), and moral licensing (Effron et al., 2009) would be particularly informative. For example, to the extent that an effect is due to a motivational shift away from "haveto" goals, it should disappear if strong incentives to perform well on the second task are introduced. By contrast, to the extent that the effect is due to actual cog- 
nitive depletion, it should be relatively unaffected by incentives. Finally, to the extent that licensing is responsible for the effect, it should diminish when the second task has clear rather than ambiguous moral implications (Merritt et al., 2010). For the time being, however, it can be concluded that working on a task that has moral implications increases engagement of the central executive. Although this response is highly adaptive during the focal task, it ironically impairs subsequent perspective taking. This, in turn, may have negative consequences for a broad range of behaviors in the moral domain.

\section{REFERENCES}

Achtziger, A., Alós-Ferrer, C., \& Wagner, A. K. (2015). Money, depletion, and prosociality in the dictator game. Journal of Neuroscience, Psychology, and Economics, 8, $1-14$.

Apperly, I. A., Samson, D., \& Humphreys, G. W. (2009). Studies of adults can inform accounts of theory of mind development. Developmental Psychology, 45, 190201.

Batson, C. D., Lishner, D. A., Carpenter, A., Dulin, L., Harjusola-Webb, S., Stocks, E. L., Gale, S., Hassan, O., \& Sampat, B. (2003). "...As you would have them do unto you": Does imagining yourself in the other's place stimulate moral action? Personality and Social Psychology Bulletin, 29, 1190-1201.

Batson, C. D., Polycarpou, M. P., HarmonJones, E., Imhoff, H. J., Mitchener, E. C., Bednar, L. L., et al. (1997). Empathy and attitudes: Can feeling for a member of a stigmatized group improve feelings toward the group? Journal of Personality and Social Psychology, 72, 105-118.

Bellgrove, M. A., Hester, R., \& Garavan, H. (2004). The functional neuroanatomical correlates of response variability: Evidence from a response inhibition task. Neuropsychologica, 42, 1910-1916.

Boksem, M. A. S., Meijman, T. F., \& Lorist, M. M. (2006). Mental fatigue, motivation and action monitoring. Biological Psycho$\log y, 72,123-132$.

Brambilla, M., \& Leach, C. W. (2014). On the importance of being moral: The distinctive role of morality in social judgment. Social Cognition, 32, 397-408.

Brown-Schmidt, S. (2009). The role of executive function in perspective taking dur- ing online language comprehension. Psychonomic Bulletin and Review, 16, 893900.

Carlson, S. M., Mandell, D. J., \& Williams, L. (2004). Executive function and theory of mind: Stability and prediction from ages 2 to 3. Developmental Psychology, 6, $1105-1122$

Carlson, S. M., Moses, L. J., \& Breton, C. (2002). How specific is the relation between executive function and theory of mind? Contributions of inhibitory control and working memory. Infant and Child Development, 11, 73-92.

Carlson, S. M., Moses, L. J., \& Claxton, L. J. (2004). Individual differences in executive functioning and theory of mind: An investigation of inhibitory control and planning ability. Journal of Experimental Child Psychology, 87, 299-319.

Chuah, Y. M., Venkatraman, V., Dinges, D. F., \& Chee, M. W. (2006). The neural basis of interindividual variability in inhibitory efficiency after sleep deprivation. Journal of Neuroscience, 26, 7156-7162.

Davis, M. H. (1983). Measuring individual differences in empathy: Evidence for a multidimensional approach. Journal of Personality and Social Psychology, 44, 113126.

DeWall, C. N., Baumeister, R. F., Stillman, T. F., \& Galliot, M. T. (2007). Violence restrained: Effects of self-regulation and its depletion on aggression. Journal of Experimental Social Psychology, 43, 62-76.

Dovidio, J. F., ten Vergert, M., Stewart, T. L., Gaertner, S. L., Johnson, J. D., Esses, V. M., Riek, B. M., \& Pearson, A. R. (2004). Perspective and prejudice: Antecedents and mediating mechanisms. Personality 
and Social Psychology Bulletin, 30, 15371549.

Effron, D. A., Cameron, J. S., \& Monin, B. (2009). Endorsing Obama licenses favoring Whites. Journal of Experimental Social Psychology, 45, 590-593.

Eisenberg, N., \& Miller, P. A. (1987). The relation of empathy to prosocial and related behaviors. Psychological Bulletin, 101, 91119.

Ellemers, N., Pagliaro, S., \& Barreto, M. (2013). Morality and behavioural regulation in groups: A social identity approach. European Review of Social Psychology, 24, 160-193.

Ellemers, N., Pagliaro, S., Barreto, M., \& Leach, C. W. (2008). Is it better to be moral than smart? The effects of morality and competence norms on the decision to work at group status improvement. Journal of Personality and Social Psychology, 95, 1397-1410.

Ellemers, N., \& Van den Bos, K. (2012). Morality in groups: On the social-regulatory functions of right and wrong. Social and Personality Psychology Compass, 6, 878889.

Epley, N., Keysar, B., Van Boven, L., \& Gilovich, T. (2004). Perspective taking as egocentric anchoring and adjustment. Journal of Personality and Social Psychology, 87, 327-339.

Fennis, B. M. (2011). Can't get over me: Ego depletion attenuates prosocial effects of perspective taking. European Journal of Social Psychology, 41, 580-585.

Fjell, A. M., Westlye, L. T., Amlien, I. K., \& Walhovd, K. B. (2011). Reduced white matter integrity is related to cognitive instability. Journal of Neuroscience, 31, 18060-18072.

Gino, F., Schweitzer, M. E., Mead, N. L., \& Ariely, D. (2011). Unable to resist temptation: How self-control depletion promotes unethical behavior. Organizational Behavior and Human Decision Processes, 115, 191-203.

Hagger, M. S., Wood, C., Stiff, C., \& Chatzisarantis, N. L. (2010). Ego depletion and the strength model of self-control: A meta-analysis. Psychological Bulletin, 136, 495-525.

Hayes, A. F. (2013). Introduction to mediation, moderation, and conditional process analysis. New York: Guilford.
Hughes, C., \& Ensor, R. (2007). Executive function and theory of mind: Predictive relations from ages 2 to 4 . Developmental Psychology, 43, 1447-1459.

Inzlicht, M., \& Gutsell, J. N. (2007). Running on empty: Neural signals for self-control failure. Psychological Science, 18, 933-937.

Inzlicht, M., McKay, L., \& Aronson, J. (2006). Stigma as ego depletion: How being the target of prejudice affects self-control. Psychological Science, 17, 262-269.

Inzlicht, M., \& Schmeichel, B. J. (2012). What is ego depletion? Toward a mechanistic revision of the resource model of selfcontrol. Perspectives on Psychological Science, 7, 450-463.

Inzlicht, M., Schmeichel, B. J., \& Macrae, C. N. (2014). Why self-control seems (but may not be) limited. Trends in Cognitive Sciences, 18, 127-133.

Jensen, A. R. (1992). The importance of intraindividual variation in reaction time. Personality and Individual Differences, 13, 869-881.

Johns, M., Inzlicht, M., \& Schmader, T. (2008). Stereotype threat and executive resource depletion: Examining the influence of emotion regulation. Journal of Experimental Psychology: General, 137, 691-705.

Johnson, K. A., Kelly, S. P., Bellgrove, M. A., Barry, E., Cox, M., Gill, M., et al. (2007). Response variability in attention deficit hyperactivity disorder: Evidence for neuropsychological heterogeneity. Neuropsychologica, 45, 630-638.

Keysar, B. (1994). The illusory transparency of intention: Linguistic perspective taking in text. Cognitive Psychology, 23, 165-208.

Kinderman, P., Dunbar, R., \& Bentall, R. P. (1998). Theory-of-mind deficits and causal attributions. British Journal of Psychology, 89, 191-204.

Koch, S., Holland, R. W., Hengstler, M., \& van Knippenberg, A. (2009). Body locomotion as regulatory process: Stepping backward enhances cognitive control. Psychological Science, 20, 549-550.

Koch, S., Holland, R. W., \& van Knippenberg, A. (2008). Regulating cognitive control through approach-avoidance motor actions. Cognition, 109, 133-142.

Lamm, C. Batson, C. D., \& Decety, J. (2007). The neural substrate of human empathy: Effects of perspective-taking and 
cognitive appraisal. Journal of Cognitive Neuroscience, 19, 42-58.

Leach, C. W., Ellemers, N., \& Barreto, M. (2007). Group virtue: The importance of morality (vs. competence and sociability) in the positive evaluation of ingroups. Journal of Personality and Social Psychology, 93, 234-249.

Manly, T., Davison, B., Heutink, J., Galloway, M., \& Robertson, I. H. (2000). Not enough time, or not enough attention?: Speed, error, and self-maintained control in the sustained attention to response test (SART). Clinical Neuropsychological Assessment, 3, 167-177.

Mead, N. L., Baumeister, R. F., Gino, F., Schweitzer, M. E., \& Ariely, D. (2009). Too tired to tell the truth: Self-control resource depletion and dishonesty. Journal of Experimental Social Psychology, 45, 594-597.

Merritt, A. C., Effron, D. A., \& Monin, B. (2010). Moral self-licensing: When being good frees us to be bad. Social and Personality Psychology Compass, 4, 344-357.

Monin, B., \& Miller, D. T. (2001). Moral credentials and the expression of prejudice. Journal of Personality and Social Psycholo$g y, 81,33-43$.

Muraven, M., \& Baumeister, R. F. (2000). Selfregulation and depletion of limited resources: Does self-control resemble a muscle? Psychological Bulletin, 126, 247259.

Nilsen, E. S., \& Graham, S. A. (2009). The relations between children's communicative perspective-taking and executive functioning. Cognitive Psychology, 58, 220-249.

Pagliaro, S., Brambilla, M., Sacchi, S., D'Angelo, M., \& Ellemers, N. (2013). Initial impressions determine behaviours: Morality predicts the willingness to help newcomers. Journal of Business Ethics, 117, 37-44.

Pellicano, E. (2007). Links between theory of mind and executive function in young children with autism: Clues to developmental primacy. Developmental Psychology, 43, 974-990.

Rauch, W. A., \& Schmitt, K. (2009). Fatigue of cognitive control in the Stroop task. In N. A. Taatgen \& H. van Rijn (Eds.), Proceedings of the 31st Annual Conference of the Cognitive Science Society (pp. 750-
755). Austin, TX: Cognitive Science Society.

Richeson, J. A., Baird, A. A., Gordon H. L., Heatherton, T. F., Wyland, C. L., Trawalter, S., \& Shelton, J. N. (2003). An fMRI investigation of the impact of interracial contact on executive function. Nature Neuroscience, 6, 1323-1328.

Richeson, J. A., \& Shelton, J. N. (2003). When prejudice does not pay: Effects of interracial contact on executive function. Psychological Science, 14, 287-290.

Sassenrath, C., Sassenberg, K., \& Scholl, A. (2014). From a distance...: The impact of approach and avoidance motivational orientation on perspective taking. Social Psychological and Personality Science, 5, 18-26.

Shammi, P., Bosman, E., \& Stuss, D. T. (1998). Aging and variability in performance. Aging, Neuropsychology, and Cognition, $5,1-13$

Simmonds, D. J., Fotedar, S. G., Suskauer, S. J., Pekar, J. J., Denckla, M. G., \& Mostofsky, S. H. (2007). Functional brain correlates of response time variability in children. Neuropsychologica, 45, 2147-2157.

Skowronski, J. J., \& Carlston, D. E. (1987). Social judgment and social memory: The role of cue diagnosticity in negativity, positivity, and extremity biases. Journal of Personality and Social Psychology, 52, 689-699.

Ståhl, T., Van Laar, C., \& Ellemers, N. (2012). The role of prevention focus under stereotype threat: Initial cognitive mobilization is followed by depletion. Journal of Personality and Social Psychology, 102, 1239-1251.

Stroop, J. R. (1935). Studies of interference in serial verbal reactions. Journal of Experimental Psychology, 18, 643-662.

Stucke, T. S., \& Baumeister, R. F. (2006). Ego depletion and aggressive behavior: Is the inhibition of aggression a limited resource? European Journal of Social Psychology, 36, 1-13.

Stuss, D. T., Murphy, K. J., Binns, M. A., \& Alexander, M. P. (2003). Staying on the job: The frontal lobes control individual performance variability. Brain, 126, 23632380.

Swick, D., Honzel, N., Larsen, J., \& Ashley, V. (2013). Increased response variability as a marker of executive dysfunction in 
veterans with post-traumatic stress disorder. Neuropsychologica, 51, 3033-3040.

Tamm, L., Nara, M. E., Antonini, T. M., O'Brien, K. M., Hawk, L. W., Jr., \& Epstein, J. N. (2012). Reaction time variability in ADHD: A review. Neurotherapeutics, 9, 500-508.

Todd, A. R., Bodenhausen, G. V., Richeson, J. A., \& Galinsky, A. D. (2011). Perspective taking combats automatic expressions of racial bias. Journal of Personality and Social Psychology, 100, 1027-1042.

Underwood, B., \& Moore, B. (1982). Perspective-taking and altruism. Psychological Bulletin, 91, 143-173.

Van Nunspeet, F., Derks, B., Ellemers, N., \& Nieuwenhuis, S. (2015). Moral impression management: Evaluation by an in-group member during a moral IAT affects perceptual attention and conflict and response monitoring. Social Psychological and Personality Science, 6, 183-192.

Van Nunspeet, F., Ellemers, N., Derks, B., \& Nieuwenhuis, S. (2014). Moral concerns increase attention and response monitoring during IAT performance: ERP evidence. Social, Cognitive and Affective Neuroscience, 9, 141-149.

Vohs, K. D., Glass, B. D., Maddox, W. T., \& Markman, A. B. (2011). Ego depletion is not just fatigue: Evidence from a total sleep deprivation experiment. Social Psychological and Personality Science, 2, 166-173.

Wardlow, L. (2013). Individual differences in speakers' perspective taking: The roles of executive control and working memory. Psychonomic Bulletin and Review, 20, 766-772.

West, R., Murphy, K. J., Armilio, M. S., Craik, F. I., \& Stuss, D. T. (2002). Lapses of intention and performance variability reveal age-related increases in fluctuations of executive control. Brain and Cognition, 49, 402-419. 